\title{
Avaliando os Impactos de Políticas Tributárias sobre a Economia Brasileira com Base em um Modelo de Equilíbrio Geral de Gerações Sobrepostas
}

\author{
Carlos Renato Salami*, Adelar Fochezatto ${ }^{\dagger}$
}

\author{
Contents: 1. Introdução; 2. Estrutura do Modelo; 3. Simulações e Análise dos Resultados; \\ 4. Comentários Finais. \\ Keywords: Economia Brasileira; Reforma Tributária; Modelos de Equilíbrio Geral \\ Computável. \\ JEL Code: E62; 668 .
}

O objetivo deste trabalho é analisar os efeitos econômicos de longo prazo de diferentes opções tributárias utilizando um modelo de equilíbrio geral intertemporal com gerações sobrepostas. Considerando o aumento do produto e do emprego como critério para identificar as melhores políticas, os resultados permitem afirmar que: se o objetivo é reduzir a carga tributária, a política recomendada é diminuir os impostos diretos; e se o objetivo é substituir diferentes tipos de impostos, mantendo inalterada a carga tributária, a recomendação é reduzir os impostos diretos e aumentar os indiretos. The objective of this study is to analyze the long-term economic effects of different tax options using an intertemporal general equilibrium model with overlapping generations. Considering the increase in output and employment as a criterion to identify the best policies, the results show that: if the objective is to reduce the tax burden, the recommended policy is to reduce direct taxes, and if the objective is to replace various types of taxes, keeping unchanged the tax burden, the recommendation is to reduce direct taxes and increase indirect taxes ones.

\section{INTRODUÇÃO}

O sistema tributário atualmente em vigor no Brasil, implementado a partir da Reforma Constitucional de 1988, foi concebido a fim de atenuar as distorções existentes na estrutura tributária herdada do período militar. Isto foi feito por meio da reformulação na repartição das receitas públicas com vistas

\footnotetext{
* Mestre em Economia do Desenvolvimento. Professor da PUCRS. Rua Laurindo, 134/405, Bairro Santana, CEP 9 0040-140. Porto Alegre/RS. E-mail: csalami@uol.com.br

${ }^{\dagger}$ Doutor em Economia. Professor Titular da PUCRS. Pesquisador do CNPq. Av. Neusa Brizola, 600/206, Bairro Petrópolis, CEP: 90460-230, Porto Alegre/RS. E-mail: adelar@pucrs . br
} 
à desconcentração dos recursos tributários da União em favor dos estados e municípios. Afonso et al. (2000) estima que a Reforma Constitucional tenha determinado uma perda financeira para a União da ordem de $17 \%$ de suas receitas disponíveis e um aumento médio de $13,4 \%$ para os estados e de $31 \%$ para os municípios. Além disso, os autores sustentam que a descentralização determinou perdas adicionais em termos de eficiência do sistema porque ela provocou o surgimento de falhas de coordenação entre as diferentes esferas de governo.

A partir de então, tendo em vista a redução da receita sem a contrapartida de transferência de encargos para os demais entes federados, o governo federal passou a agir no sentido de recompor as suas perdas. Isto foi feito por meio da elevação das alíquotas das contribuições sociais existentes e da criação de novas contribuições sociais. Isto porque o acréscimo de receita resultante dessas fontes não necessitava ser dividido com os demais entes federados. Sendo assim, as elevações requeridas nas alíquotas, para a obtenção de um dado acréscimo de receita, poderia ser menor do que a requerida, por exemplo, nos casos do imposto sobre produtos industrializados ou do imposto de renda. Além deste, outro esforço empreendido pela União foi a tentativa de transferir responsabilidades em relação à prestação de serviços públicos para os demais níveis de governo.

As distorções provenientes da reforma tributária de 1988 levaram à elaboração, já nos anos seguintes à sua promulgação, de muitas propostas de reformulação do sistema tributário. A última década foi marcada por um contínuo debate sobre como proceder perante a reforma do sistema com o fim de se eliminarem as suas distorções e aumentar a sua eficiência. Apesar disso, embora alguns avanços tenham ocorrido, não se consolidou no período o entendimento necessário à concretização de mudanças mais profundas. Dentre as principais distorções destacam-se a elevada regressividade, a excessiva complexidade, o alto grau de descentralização e o excesso de carga tributária global.

Inúmeros esforços têm sido realizados com o intuito de avaliar os impactos de curto e de longo prazo das diferentes propostas de alterações no sistema tributário nacional. Entretanto, haja vista a complexidade do tema, os resultados apresentados não têm sido conclusivos a ponto de facilitar a tomada de decisões. Isto talvez explique a dificuldade observada na obtenção de um consenso mínimo para a aprovação de propostas mais profundas do atual sistema tributário brasileiro. A reforma aprovada em 2003 configura um exemplo claro desta situação.

O objetivo deste trabalho consiste em realizar alguns exercícios envolvendo política tributária para verificar os seus prováveis efeitos econômicos de longo prazo. Para isso, utiliza-se um modelo de equilíbrio geral computável dinâmico com gerações sobrepostas. Tal modelo se justifica porque permite que se examinem, numa perspectiva intertemporal, os efeitos advindos de alterações tributárias sobre o bem-estar das diferentes gerações de indivíduos que integram o modelo. Trata-se, portanto, de um instrumental adequado para a análise de políticas tributárias porque, sabidamente, os seus efeitos se estendem ao longo de vários períodos de tempo.

Após esta Introdução, a Seção dois apresenta detalhadamente o modelo, bem como os procedimentos usados para a obtenção dos seus principais parâmetros; a Seção três descreve as simulações efetuadas e analisa resultados encontrados; e, finalmente, na Seção quatro aparecem as Considerações Finais.

\section{ESTRUTURA DO MODELO}

Neste trabalho utiliza-se um modelo de equilíbrio geral computável dinâmico de gerações sobrepostas. ${ }^{1}$ Em cada período, a economia inclui 11 classes etárias (gerações) de famílias, com cinco anos cada, desconsiderando-se os períodos até os 21 e após os 75 . As oito primeiras gerações são admitidas ativas e as três últimas inativas (aposentadas) e não se considera a existência de herança ou qualquer

\footnotetext{
${ }^{1}$ Trata-se, portanto, de um modelo do tipo Auerbach and Kotlikoff (1987). O modelo deste trabalho segue a estrutura apresentada por Schubert and Letournel (1991). Em princípio, quanto maior o número de gerações, melhor. No entanto, um número muito grande torna o modelo difícil de ser operado. As 11 gerações representam um meio termo e que reflete gerações de 5 anos cada.
} 
tipo de doação entre gerações. A cada cinco anos, entendida como a unidade de tempo do modelo, a geração mais velha desaparece e surge uma geração mais jovem e mais numerosa, o que configura a existência de crescimento populacional.

A economia é aberta e composta por dois setores produtivos sendo que o primeiro produz um bem demandado domesticamente, tanto para consumo quanto para investimento e o segundo produz um bem destinado à exportação. As famílias, por sua vez, podem escolher entre o consumo de um bem nacional ou um importado. Adota-se a suposição de pequeno país, significando que o preço das exportações, em moeda externa, é exógeno e que a demanda externa por produtos nacionais é infinitamente elástica. A balança comercial, no entanto, é endógena e sensível às condições internas de produção. Assim, de acordo com esta estrutura do modelo usado neste trabalho, as mudanças nas políticas fiscais podem mudar o saldo comercial. Isto, por sua vez, influencia o montante de dívida externa, a poupança macroeconômica e o estoque de capital.

\subsection{Famílias}

O modelo de Ando and Modigliani (1963) e Modigliani and Brumberg (1954) fornece a estrutura teórica para a modelagem do comportamento das famílias quanto às suas decisões de consumo e lazer. De acordo com esse modelo, as famílias escolhem os níveis de consumo e lazer corrente e futuro em função de suas expectativas de renda de todo o ciclo da vida. Quando jovens, considerando-se a falta de experiência profissional e a baixa produtividade, se supõe que as famílias tenham uma renda relativamente mais baixa. Na meia idade, quando atingem a maturidade profissional, elas conquistam o pico de renda e, ao chegar à velhice, a sua renda tende a sofrer uma queda significativa.

A trajetória da renda acima descrita configura um significativo grau de variação ao longo do ciclo da vida. Os indivíduos, no entanto, tendem a manter uma alta estabilidade do consumo intertemporalmente, o que significa que o comportamento da poupança depende do estágio do seu ciclo da vida. Assim, quando jovens, os indivíduos tendem a tomar empréstimos, na meia idade eles geram poupança suficiente para pagar os empréstimos feitos nos períodos anteriores e financiar um padrão de consumo para os períodos futuros. Na aposentadoria, sendo a renda do trabalho nula, as famílias consomem os recursos que acumularam durante a vida. Com base no exposto, adota-se, no modelo, a hipótese de que cada família maximiza a sua utilidade intertemporal com base na sua expectativa de renda ao longo do ciclo da vida.

$$
\begin{aligned}
U & =\frac{1}{1-\frac{1}{\gamma}} \sum_{t=1}^{11} \frac{1}{\left(1+\delta^{\prime}\right)^{t-1}} u\left(c_{t}, l_{t}\right)^{t-\frac{1}{\gamma}} \\
u\left(c_{t}, l_{t}\right) & =\left(c_{t}^{1-\frac{1}{\rho}}+\alpha l_{t}^{1-\frac{1}{\rho}}\right)^{\frac{1}{1-1 / \rho}}
\end{aligned}
$$

em que $c_{t}$ e $l_{t}$ representam o consumo e o lazer em cada período e os parâmetros $\gamma, \delta^{\prime}, \rho$ e $\alpha$ representam, respectivamente, a elasticidade de substituição intertemporal do consumo nas diferentes idades, a taxa de preferência pelo presente, a elasticidade de substituição entre o consumo e o lazer e a taxa de preferência pelo lazer.

A demanda agregada de consumo $\left(c_{t}\right)$ é composta pelo consumo do bem produzido nacionalmente (Bem1) e pelo bem importado (Bem2):

$$
c_{t}=\left(\alpha_{1} c_{1, t}^{1-\frac{1}{\rho_{1}}}+\left(1-\alpha_{1}\right) c_{2, t}^{1-\frac{1}{\rho_{1}}}\right)^{\frac{1}{1-1 / \rho_{1}}}
$$

sendo $\rho_{1}$ a elasticidade de substituição do consumo entre o $B e m 1$ e o $B e m 2$ e $\alpha_{1}$ o parâmetro que indica a preferência pelo bem produzido nacionalmente em relação ao bem importado. 
Em cada período, o tempo total à disposição das famílias para alocação entre consumo e lazer é normalizado igual a um, sendo as famílias pertencentes às três últimas classes de idade consideradas inativas. Tem-se, portanto, que $0<l_{t} \leq 1 \forall t=1, \ldots, 8$ e $l_{9}, l_{10}$ e $l_{11}=1$, com $\left(1-l_{t}\right)$ representando o tempo destinado ao trabalho. A restrição orçamentária intertemporal a que cada família está sujeita é dada por:

$$
w\left(1-\tau_{w}\right)\left(1-\tau_{r}\right) \sum_{t=1}^{8} \frac{h_{t}\left(1-l_{t}\right)}{\left(1+r_{m}\right)^{t-1}}+\left(1-\tau_{r}\right) \sum_{t=9}^{11} \frac{P R_{t}}{\left(1+r_{m}\right)^{t-1}}=p \sum_{t=1}^{11} \frac{c_{t}}{\left(1+r_{m}\right)^{t-1}}
$$

sendo $\tau_{w}$ a contribuição social salarial, $\tau_{r}$ o imposto de renda e $P R_{t}$ as transferências a título de aposentadoria deduzidas do imposto de renda.

O parâmetro $h_{t}$ indica a evolução do salário médio $(w)$ recebido por cada família ao longo de toda a sua vida ativa. Considera-se que, na juventude, as famílias recebam um salário relativamente inferior ao que receberão ao decorrer dos anos, com o aumento da sua qualificação e produtividade. Conforme proposto por Auerbach and Kotlikoff (1987), é utilizado neste trabalho o seguinte perfil de remuneração, expresso em termos dos anos de experiência: $h_{t}=\exp \left(a+b t+c t^{2}\right)$, com a restrição de que $\sum_{t=1}^{8} h_{t}=$ 1. O fator de desconto $1 /\left(1+r_{m}\right)$ considera a taxa de juros relevante para as famílias $\left(r_{m}\right)$, a qual deduz dos juros de mercado o imposto sobre a renda do capital $\left(\tau_{e}\right)$. Assim, $r_{m}=r\left(1-\tau_{e}\right)$. O preço $p$ representa o índice de preços ao consumidor, sendo expresso pela seguinte equação:

$$
p=(1+\tau)\left(\alpha_{1}^{\rho_{1}} p_{1}^{1-\rho_{1}}+\left(1-\alpha_{1}\right)^{\rho_{1}} p_{2}^{1-\rho_{1}}\right)^{\frac{1}{1-\rho_{1}}}
$$

na qual $\tau$ representa o imposto sobre o consumo de bens nacionais ou importados. Assim, a restrição orçamentária apresenta a seguinte propriedade:

$$
p c_{t}=(1+\tau)\left(p_{1} c_{1, t}+p_{2} c_{2, t}\right)
$$

Formalmente, considera-se que as famílias maximizam a expressão (1) sujeitas à expressão (3). As condições de primeira ordem são as seguintes:

$$
\begin{aligned}
u\left(c_{t}, l_{t}\right)^{\frac{1}{\rho}-\frac{1}{\gamma}} c_{t}^{-\frac{1}{\rho}} & =\lambda p\left(\frac{1+\delta^{\prime}}{1+r_{m}}\right)^{t-1} \\
u\left(c_{t}, l_{t}\right)^{\frac{1}{\rho}-\frac{1}{\gamma}} \alpha l_{t}^{-\frac{1}{\rho}} & =\lambda w\left(1-\tau_{w}\right)\left(1-\tau_{r}\right) h_{t}\left(\frac{1+\delta^{\prime}}{1+r_{m}}\right)^{t-1}+\mu_{t}
\end{aligned}
$$

sendo $\lambda$ o multiplicador associado à restrição orçamentária e $\mu_{t}$, com $t=1, \ldots, 8$, os multiplicadores associados às restrições impostas sobre o lazer. Conforme Schubert and Letournel (1991), a presença da limitação imposta sobre o lazer, a saber, de que $l_{9}, l_{10}$ e $l_{11}=1$, impede a resolução analítica do sistema. Entretanto, se são considerados apenas os períodos ativos, as expressões precedentes conduzem às seguintes relações:

$$
\begin{aligned}
& l_{t}=c_{t}\left(\frac{\alpha p}{w\left(1-\tau_{w}\right)\left(1-\tau_{r}\right) h_{t}}\right)^{\rho} \\
& l_{t}=l_{1}\left(\frac{1+\alpha^{\rho}\left(p /\left(w\left(1-\tau_{w}\right)\left(1-\tau_{r}\right) h_{t}\right)\right)^{\rho-1}}{1+\alpha^{\rho}\left(p /\left(w\left(1-\tau_{w}\right)\left(1-\tau_{r}\right) h_{t}\right)\right)^{\rho-1}}\right)^{\frac{\gamma-\rho}{\rho-1}} \cdot\left(\frac{1+r_{m}}{1+\delta^{\prime}}\right)^{\gamma(t-1)} \\
& c_{t}=c_{1}\left(\frac{1+\alpha^{\rho}\left(p /\left(w\left(1-\tau_{w}\right)\left(1-\tau_{r}\right) h_{t}\right)\right)^{\rho-1}}{1+\alpha^{\rho}\left(p /\left(w\left(1-\tau_{w}\right)\left(1-\tau_{r}\right) h_{t}\right)\right)^{\rho-1}}\right)^{\frac{\gamma-\rho}{\rho-1}} \cdot\left(\frac{1+r_{m}}{1+\delta^{\prime}}\right)^{\gamma(t-1)}
\end{aligned}
$$


Conhecida a demanda de consumo agregado $\left(c_{t}\right)$, as demandas dos dois bens podem ser expressas como segue:

$$
\begin{aligned}
& c_{1, t}=c_{t}\left(\frac{\alpha_{1} p}{(1+\tau) p_{1}}\right)^{\rho_{1}} \\
& c_{2, t}=c_{t}\left(\frac{\alpha_{1} p}{(1+\tau) p_{2}}\right)^{\rho_{1}}
\end{aligned}
$$

Em um modelo de gerações sobrepostas, uma condição necessária para que a poupança agregada seja positiva é que haja crescimento populacional. Isto porque, neste caso, a magnitude da poupança gerada pelos jovens supera a poupança negativa dos inativos. Admitindo-se $P$ como sendo a população total da economia em um dado momento e $n$ a sua taxa de crescimento, a população da classe etária $t$, para $t=1, \ldots, 11$, é dada por:

$$
\frac{n(1+n)^{11-t}}{(1+n)^{11}-1} P
$$

O modelo é escrito em termos do número de indivíduos da geração mais nova, que compreende $\frac{n(1+n)^{10}}{(1+n)^{11}-1} P$ pessoas. Assim, o consumo total pode ser expresso como sendo:

$$
\begin{aligned}
C & =\frac{(1+n)^{11}-1}{n(1+n)^{10}} \frac{1}{P} \sum \frac{n(1+n)^{11-t}}{(1+n)^{11}-1} P c_{t} \\
C & =\sum_{t=1}^{11} \frac{c_{t}}{(1+n)^{t-1}}
\end{aligned}
$$

Considera-se, ainda, que, ao longo da sua vida ativa, as famílias contribuem para fins de aposentadoria, na forma de pagamentos para a previdência social, e que recebem transferências a título de aposentadoria quando inativos. A partir dos dados fiscais do Brasil, pode-se dizer que o montante transferido às famílias corresponde, em média, a $70 \%$ da renda recebida ao longo da sua vida ativa, o que é expresso da seguinte forma:

$$
P R=0,7 \frac{w}{8} \sum_{t=1}^{8} h_{t}\left(1-l_{t}\right)
$$

As contribuições sociais dos trabalhadores e dos empregadores para a previdência são dadas por:

$$
C S R=P R \sum_{t=9}^{11}(1+n)^{1-t}=\left(\tau_{w r}+\tau_{r}^{\prime \prime}\right) w \sum_{t=1}^{8} h_{t}\left(1-l_{t}\right)(1+n)^{1-t}
$$

onde, $\tau_{w r}$ e $\tau_{r}^{\prime \prime}$ representam as contribuições sociais a título de aposentadoria dos trabalhadores e dos empregadores, respectivamente.

\subsection{Empresas}

A economia é composta de dois setores produtivos, sendo que o setor 1 produz para o mercado doméstico e o setor 2 para o mercado externo. Supõe-se, ademais, que a produção dos dois setores seja determinada por uma função de produção CES, com rendimentos de escala constantes. 


$$
Y_{i}=F_{i}\left(K_{i}, L_{i}\right)=A_{i}\left(\theta_{i} K_{i}^{1-\frac{1}{\sigma_{i}}}+\left(1-\theta_{i}\right) L_{i}^{1-\frac{1}{\sigma_{i}}}\right)^{\frac{1}{1-\frac{1}{\sigma_{i}}}} \quad \text { para } \quad i=1,3
$$

As variáveis $Y_{i}, K_{i}$ e $L_{i}$ representam, respectivamente, a produção, o capital e o nível de emprego do setor $i$. O parâmetro $A_{i}$ é considerado um fator de escala e representa a produtividade total dos fatores. o parâmetro $\sigma_{i}$ expressa a elasticidade de substituição entre capital e trabalho e $\theta_{i}$ a participação do capital na função de produção.

As empresas maximizam seus lucros intertemporalmente, sujeitas à restrição advinda dos custos de produção:

$$
\Pi_{i}=\left(p_{i} Y_{i}-s\left(1+\tau_{r}^{\prime \prime}\right) L_{i}-p_{i}(r+\delta) K_{i}\right)\left(1-\tau^{\prime}\right) \quad \text { para } \quad i=1,3
$$

onde, $p_{1}$ e $p_{3}$ correspondem aos preços dos bens 1 e 3, $r$ é a taxa de juros real, $\delta$ a taxa de depreciação do capital, $s$ o salário médio pago pelas empresas, $\tau_{r}^{\prime \prime}$ a contribuição social paga pelos empregadores e $\tau^{\prime}$ o imposto sobre o lucro.

o Bem1 é utilizado também como bem de capital sendo a importação desse tipo de bem nula. Embora as empresas estejam sujeitas aos custos de ajustamento do capital no estado transitório, estes desaparecem no estado estacionário de longo prazo. Nestas circunstâncias, o investimento compreende, de um lado, a depreciação do capital e, de outro, o crescimento do estoque de capital à taxa de crescimento populacional. Tem-se, portanto que $I_{i}=(\delta+n) K_{i}$. A partir da resolução do problema de maximização do lucro das empresas, obtêm-se as seguintes expressões para as demandas por capital e trabalho e para a fronteira dos preços dos fatores. ${ }^{2}$

$$
\begin{aligned}
K_{i} & =Y_{i} A_{i}^{\sigma_{i}-1}\left(\frac{\theta_{i} p_{i}}{r+\delta}\right)^{\sigma_{i}} \\
L_{i} & =Y_{i} A_{i}^{\sigma_{i}-1}\left(\frac{\left(1-\theta_{i}\right) p_{i}}{s\left(1-\tau_{r}^{\prime \prime}\right)}\right)^{\sigma_{i}} \\
\left(p_{i} A_{i}\right)^{1-\sigma_{i}} & =\theta_{i}^{\sigma_{i}}(r+\delta)^{1-\sigma_{i}}+(1-\theta)^{\sigma_{i}}\left(s\left(1+\tau_{r}^{\prime \prime}\right)\right)^{1-\sigma_{i}}
\end{aligned}
$$

No que tange ao mercado de trabalho, tem-se que a relação entre o salário médio pago pelos empregadores $(s)$ e o salário médio recebido pelos trabalhadores ao longo da sua vida ativa é definida da seguinte forma:

$$
s \sum_{t=1}^{8} \frac{1-l_{t}}{(1+n)^{t-1}}=w \sum_{t=1}^{8} \frac{h_{t}\left(1-l_{t}\right)}{(1+n)^{t-1}}
$$

\subsection{Governo}

O Estado arrecada receitas fiscais e é consumidor tanto de bens produzidos nacionalmente quanto de bens importados:

$$
R F-\left(p_{1} G_{1}+p_{2} G_{2}\right)=(r-n) D
$$

sendo $R F$ o montante de receitas fiscais, $G_{1}$ e $G_{2}$ as despesas com os bens 1 e 2 e $D$ o montante da dívida pública, na forma de títulos públicos.

\footnotetext{
${ }^{2}$ Conforme Schubert and Letournel (1991), a fronteira dos preços dos fatores ou condição de lucro nulo decorre da hipótese da constância dos rendimentos de escala, o que determina que a relação entre os preços dos fatores depende apenas dos parâmetros da função de produção.
} 
A capacidade de financiamento do Estado lhe permite o pagamento dos encargos sobre a dívida, representados pela diferença entre a taxa de juros real e a taxa de crescimento populacional. A função receita fiscal explicitando as diferentes fontes de receitas do Estado é definida pela seguinte equação:

$$
R F=\tau_{r} w\left(1-\tau_{w}\right) \sum_{t=1}^{8} \frac{h_{t}\left(1-l_{t}\right)}{(1+n)^{t-1}}+\tau_{r} P R \sum_{i=9}^{11} \frac{1}{(1+n)^{t-1}}+\tau\left(p_{1} C B_{1}+p_{2} C B_{2}\right)+r \tau_{e} \frac{E}{1+n}
$$

sendo $E$ definido como a soma ponderada dos montantes de poupança de um consumidor pertencente a cada classe etária, $E_{t}$. Tem-se, portanto, que:

$$
\begin{aligned}
E & =\sum_{i=1}^{10} \frac{E_{t}}{(1+n)^{t-1}} \\
E_{1} & =w\left(1-\tau_{w}\right)\left(1-\tau_{r}\right) h_{1}\left(1-l_{1}\right)-p c_{1} \\
E_{t} & =w\left(1-\tau_{w}\right)\left(1-\tau_{r}\right) h_{t}\left(1-l_{t}\right)+\left(1+r_{m}\right) E_{t-1}-p c_{t} ; t=2, \cdots, 8 \\
E_{t} & =P R\left(1-\tau_{r}\right)+\left(1+r_{m}\right) E_{t-1}-p c_{t} ; t=9,10
\end{aligned}
$$

A poupança líquida da economia é calculada, considerando-se a poupança negativa das gerações mais velhas, da seguinte forma:

$$
E M=\left(1-\frac{1}{1+n}\right) E
$$

\subsection{Equilíbrio dos mercados}

Formalizado o comportamento de cada agente econômico que integra o modelo, passa-se, a seguir, a considerar as condições de equilíbrio que devem ser satisfeitas, em cada um dos mercados, para que seja obtida a resolução numérica do modelo. ${ }^{3}$ Serão explicitadas as condições de equilíbrio do mercado de trabalho, do mercado do Bem 1 e da balança comercial, sendo o equilíbrio do mercado de capitais definido pela lei de Walras. ${ }^{4}$

No mercado de trabalho, o equilíbrio é expresso pela igualdade entre a oferta e a demanda de trabalho.

$$
L_{1}+L_{3}=\sum_{t=1}^{8} \frac{1-l_{t}}{(1+n)^{t-1}}
$$

onde, $L_{1}$ e $L_{3}$ representam as demandas de trabalho nos setores produtores dos bens 1 e 3 , respectivamente, e a expressão do lado direito representa a oferta de trabalho total das oito gerações ativas que compõem o modelo.

No mercado do Bem1, produzido nacionalmente, supõe-se que seja satisfeita a seguinte condição de equilíbrio:

$$
Y_{1}=C B_{1}+(n+\delta)\left(K_{1}+K_{3}\right)+G_{1}
$$

sendo $n+\delta)\left(K_{1}+K_{3}\right)$ a demanda de investimento dos dois setores produtivos e $C B_{1}$ o consumo total do Bem1.

\footnotetext{
${ }^{3}$ Todas as igualdades em consideração se referem ao estado estacionário.

${ }^{4}$ De acordo com a Lei de Walras, a soma dos valores dos excessos de demanda agregados na economia deve ser igual à zero. Assim, em uma economia com $n$ mercados, se $n-1$ estiverem em equilíbrio, o $n$-ésimo também estará.
} 
O saldo efetivo da balança comercial é o seguinte:

$$
B C=p_{3} Y_{3}-p_{2}\left(C B_{2}+G_{2}\right)
$$

No que se refere ao relacionamento da economia com o resto do mundo, considera-se que o Brasil é uma pequena economia aberta. Assim, o preço é dado pelo mercado internacional e a demanda por exportações é infinitamente elástica. Neste caso, sob a hipótese de perfeita mobilidade de capitais, o país não exerce nenhuma influência sobre a taxa de juros mundial, sendo, portanto, a taxa de juros doméstica exógena e igual à taxa de juros mundial.

Sendo $D X$ a dívida externa do país, no estado estacionário satisfaz-se a seguinte relação:

$$
(r-n) D X=B C
$$

Finalmente, pela lei de Walras, obtém-se o equilíbrio do mercado de capitais:

$$
\frac{E}{(1+n)}=\frac{E M}{n}=\left(K_{1}+K_{3}\right)+(D-D X)
$$

Tem-se, portanto, que a poupança líquida financia o estoque de capital da economia, bem como o excedente da dívida pública em relação à dívida externa.

O conjunto de equações apresentado nesta seção possibilita que se tenha uma idéia do comportamento dos diferentes agentes e do funcionamento dos diferentes mercados que integram o modelo. A seguir, proceder-se-á à parametrização e à calibragem dos parâmetros necessários para a resolução numérica do modelo.

\subsection{Calibragem do modelo}

Nos modelos de equilíbrio geral computável, a calibragem consiste no procedimento que possibilita a reprodução dos dados do ano base como solução do modelo. Isto exige a construção de um amplo e consistente banco de dados. Ele inclui os valores de todas as variáveis do modelo, geralmente expressos na forma de uma matriz de contabilidade social, elaborada a partir das contas nacionais e de diversas outras fontes estatísticas. A calibragem consiste na resolução das equações na forma inversa, sendo os valores dos parâmetros calculados por meio da fixação dos valores das variáveis endógenas nos níveis observados no período de referência. Além disso, é necessário especificar valores de alguns parâmetros não passíveis de calibragem, os quais são tirados da literatura pertinente.

Os dados utilizados na calibragem do modelo correspondem à média dos cinco anos compreendidos entre 1994 e 1998, período de estabilidade cambial. Os principais agregados macroeconômicos, extraídos das contas nacionais e de outras fontes, utilizados no modelo estão na Tabela 1. De acordo com os dados do IBGE, a despesa do setor público consolidado, que inclui os gastos da administração direta federal, dos estados, dos municípios, das empresas públicas, do banco central e da seguridade social, atingiu, em média, 27,6\% do PIB no período, dos quais o pagamento de benefícios pelo Regime Geral da Previdência Social representou, aproximadamente, 4,6\% do PIB. Dessa forma, pela ótica do resultado primário, o setor público apresentou uma situação de equilíbrio fiscal. Entretanto, após a inclusão dos gastos com o pagamento de juros sobre a dívida pública, de aproximadamente 4,7\% do PIB, o equilíbrio primário transforma-se em um déficit da ordem de $4,5 \%$ do PIB. Outras variáveis importantes são: a dívida líquida do setor público e a taxa real de juros. O primeiro representou, em média, 25,6\% do PIB no período. ${ }^{5}$ Em relação aos juros, foi utilizada a média da taxa de longo prazo, que ficou em $16,5 \%$ no período.

Em relação aos setores produtivos que integram o modelo, supõe-se que os dois setores utilizam igual tecnologia. Isto significa que eles possuem as mesmas elasticidades de substituição $\left(\sigma_{1}=\sigma_{3}=\right.$

\footnotetext{
${ }^{5}$ Excluindo a base monetária.
} 
Table 1: Principais agregados macroeconômicos do modelo (\% do PIB)

\begin{tabular}{|l|c|c|}
\hline Agregados macroeconômicos & Participação no PIB (\%) & Fonte \\
\hline \multicolumn{2}{|c|}{ Informações provenientes das contas nacionais } \\
\hline Consumo final das famílias $(C)$ & 61,6 & IBGE \\
Consumo final da administração pública $(G)$ & 18,7 & IBGE \\
Formação bruta de capital $(I)$ & 21,5 & IBGE \\
Exportações $(X)$ & 7,6 & IBGE \\
Importações $(M) \quad 9,4$ & IBGE \\
\hline \multicolumn{2}{|c|}{ Informações provenientes de outras fontes estatísticas } \\
\hline Estoque de capital & 300 & Lledo (2001) \\
Carga tributária (exclusive seguridade social) & 21,43 & SRF \\
Contribuições para a seguridade social & 6,38 & MPAS \\
Gastos do governo com benefícios & 4,6 & MPAS \\
Pagamento de juros sobre a dívida pública & 4,7 & SRF \\
Dívida pública total do setor público & 34,1 & SRF \\
\hline
\end{tabular}

Fonte: IBGE, MPAS, SRF, Lledo (2001).

$\sigma)$, a mesma participação do capital na função de produção $\left(\theta_{1}=\theta_{3}=\theta\right)$ e as mesmas produtividades totais dos fatores $\left(A_{1}=A_{3}=A\right)$. Tais hipóteses implicam na igualdade dos preços praticados pelos dois setores produtivos: $p_{1}=p_{3}$.

o preço do $B e m 1$ é utilizado como numerário, sendo, portanto, $p_{1}=1$ e o do $B e m 2\left(p_{2}\right)$ é fixado pelo resto do mundo, em moeda estrangeira. Assim, sendo $e$ a taxa de câmbio, o preço do $B e m 2$, em moeda doméstica, é $p_{2}=e \dot{p_{2}}$. Além disso, impondo-se que $\dot{p_{2}}=1$, resulta que $p_{2}=e$. Finalmente, $o$ preço do $B e m 3$ se expressa como $p_{3}=e \dot{p_{3}}$, sendo $\dot{p_{3}}$ o preço das exportações em moeda estrangeira. Portanto, da mesma forma, considerando-se que $\dot{p_{3}}=1$, tem-se que $p_{3}=e$.

O perfil de remuneração individual descreve os salários relativos por idade. Auerbach and Kotlikoff (1987) definem em seu trabalho o perfil de remuneração do trabalho como uma função exponencial dos anos de experiência, da seguinte forma: $e_{t}=\exp \left(a+b t+c t^{2}\right)$. A partir desta especificação funcional, se utiliza as estimativas obtidas por Ferreira and Araújo (1999), ${ }^{6}$ o qual obteve os seguintes valores para os parâmetros: $a=-0,231, b=0,05$ e $c=-0,0009$. A partir destas estimativas foi feita a calibragem dos parâmetros pertencentes ao perfil de remuneração, os quais aparecem na Tabela 2.

Table 2: Parâmetros que definem o perfil de remuneração do trabalho

\begin{tabular}{|c|c|c|c|c|c|c|c|}
\hline$h_{1}$ & $h_{2}$ & $h_{3}$ & $h_{4}$ & $h_{5}$ & $h_{6}$ & $h_{7}$ & $h_{8}$ \\
\hline 0,79 & 0,85 & 0,90 & 1,0 & 1,05 & 1,09 & 1,14 & 1,18 \\
\hline
\end{tabular}

Fonte: Cálculo dos autores.

Apesar de $h_{t}$ e $w$ serem exógenos, pela expressão 23 o salário efetivo torna-se endógeno e dependente do lazer, $l t$, que, por sua vez, depende do preço dos produtos e dos impostos.

\footnotetext{
${ }^{6}$ Ferreira and Araújo (1999) estimam os valores dos parâmetros que refletem o retorno da experiência de residentes em área urbana com idade entre 25 e 65 anos, utilizando a Pesquisa Nacional por Amostra de Domicílios (PNAD).
} 
Os parâmetros calculados pelo processo de calibragem e os obtidos diretamente de outras fontes estão na Tabela 3.

O modelo inclui, ainda, os parâmetros fiscais e previdenciários que compõem a matriz tributária do Brasil. Para ajustar ao modelo usado, procedeu-se a agregação dos diferentes impostos em quatro categorias. A Tabela 4 apresenta as alíquotas destas categorias.

Table 3: Valores dos parâmetros usados no modelo ${ }^{7}$

\begin{tabular}{|l|c|c|}
\hline Parâmetros & Valores & Fonte \\
\hline Preferência das famílias pelos bens na- & 0,77 & Calibragem \\
cionais $\left(\alpha_{1}\right)$ & 0,72 & Calibragem \\
Preferência das famílias pelo lazer $(\alpha)$ & 0,97 & Calibragem \\
Participação do capital na produção $(\theta)$ & 3,71 & Calibragem \\
Produtividade total dos fatores $(A)$ & 0,11 & Calibragem \\
Contribuição previdenciária dos empre- & & \\
gadores $\left(\tau_{r}^{\prime \prime}\right)$ & 0,47 & Mercenier and Sampaio de Souza (1994) \\
Elasticidade de substituição capital tra- & & Lledo (2001) \\
balho $(\sigma)$ & $5,0 \%$ a.a. & Lledo (2001) \\
Taxa de depreciação do capital $(\delta)$ & $2,1 \%$ a.a. & Lledo (2001) \\
Taxa de preferência pelo presente $\left(\delta^{\prime}\right)$ & 0,40 & Tourinho et al. (2002) \\
Elasticidade de substituição intertemporal & \\
do consumo $(\gamma)$ & 1,15 & IBGE (1994,1998) \\
Elasticidade de substituição entre consumo & & Ipeadata \\
e lazer $(\rho)$ & 1,41 & \\
Elasticidade de substituição entre o Bem1 & & \\
e o $B e m 2\left(\rho_{1}\right)$ & $1,90 \%$ a.a. \\
Taxa de crescimento populacional $(n)$ & $7,54 \%$ a.a. & \\
Taxa de juro real $(r)$ & & \\
\hline
\end{tabular}

Fonte: Elaboração dos autores.

Table 4: Alíquotas tributárias efetivas ajustadas à estrutura do modelo ${ }^{8}$

\begin{tabular}{|l|c|}
\hline Impostos & Alíquotas (\%) \\
\hline Imposto sobre o consumo & $\tau=15,68$ \\
Imposto sobre o rendimento da poupança & $\tau_{e}=13,21$ \\
Imposto sobre a renda & $\tau_{r}=11,82$ \\
Contribuição previdenciária salarial & $\tau_{w r}=4,03$ \\
\hline
\end{tabular}

Fonte: Cálculo dos autores.

\footnotetext{
${ }^{7}$ Os parâmetros $\theta, A$ e $\alpha_{1}$ são obtidos a partir das seguintes expressões: $A=\left[\theta^{\sigma}(r+\delta)^{1-\sigma}+(1-\theta)^{\sigma}(s(1+\right.$ $\left.\left.\left.\tau^{\prime \prime}\right)\right)^{1-\sigma}\right]^{1 / 1-\sigma} / p_{1} ; \theta=\left[\left(\frac{K}{L}\right)^{1 / \sigma} \cdot \frac{r+\delta}{s\left(1+\tau_{r}^{\prime \prime}\right)}\right] /\left[1+\left(\frac{K}{L}\right)^{1 / \sigma} \cdot \frac{r+\delta}{s\left(1+\tau_{r}^{\prime \prime}\right)}\right] ;$ e $\alpha_{1}=1 /\left[1+\left(\frac{c_{2}}{c_{1}}\right)^{1 / \rho_{1}}\right]$.
} 


\section{SIMULAÇÕES E ANÁLISE DOS RESULTADOS}

Determinado o equilíbrio estacionário de referência, serão procedidas a seguir algumas simulações envolvendo alterações na política fiscal do governo. ${ }^{9}$ É importante notar que, com exceção das duas primeiras simulações, as demais são efetuadas a partir de modificações fiscais que contemplam a manutenção das receitas fiscais no nível anterior à mudança. Tal imposição facilita a análise comparativa das diferentes simulações. Esta condição determina que a dívida interna permaneça estável. Isto porque, no caso da economia aberta, não há a possibilidade das modificações fiscais provocarem variações na taxa de juros doméstica, a qual tende a igualar-se à taxa mundial.

É oportuno salientar também que não é intenção, com as simulações, tentar determinar o sistema fiscal que fornece o montante de receitas fiscais ótimo, no sentido de induzir o maior nível de bem-estar possível. O que se pretende é efetuar algumas alterações marginais na estrutura tributária atual da economia com o intuito de se analisar as suas influências sobre a atividade econômica no longo prazo. As simulações são as seguintes:

Sim-1) redução de 9,81\% na alíquota do imposto sobre o valor agregado;

Sim-2) redução de $14,77 \%$ no imposto de renda;

Sim-3) redução de $9,81 \%$ na alíquota do imposto sobre o valor agregado, compensada pela introdução de um imposto lump-sum;

Sim-4) redução de 14,77\% no imposto de renda, compensada pela introdução de um imposto lump-sum; e

Sim-5) redução de $9,81 \%$ do imposto sobre o valor agregado, compensada pelo aumento de $14,78 \%$ no imposto de renda.

As duas primeiras simulações resultam em um nível inferior de arrecadação tributária de exatamente 5\%. Objetiva-se, com estas simulações, verificar a proposição comumente defendida de que a redução de impostos geraria um estímulo à atividade econômica cujo impacto na arrecadação seria suficiente para compensar a redução inicial do imposto. Nas três últimas simulações, considera-se que a redução de um imposto seja compensada, sob o ponto de vista das receitas, pela elevação de outro imposto. Pretende-se, com estas três últimas simulações, fazer uma análise comparativa das diferentes opções fiscais em termos de impactos favoráveis sobre a economia. Os resultados de todas as simulações são apresentados na Tabela 5 e, como ela é auto-explicativa, analisam-se apenas os resultados considerados mais relevantes.

\subsection{Simulação 1: Redução do imposto sobre o valor agregado}

A redução do imposto sobre o valor agregado apresenta como impacto inicial a diminuição do preço do consumo interno $(p)$, o que favorece a expansão do consumo da população ativa em virtude de dois efeitos. Em primeiro lugar, porque a redução do preço causa a elevação do salário real $(w / p)$, possibilitando aos assalariados desfrutar de um nível mais elevado de consumo. Por outro lado, à medida que o lazer se torna relativamente mais caro, os trabalhadores são incentivados a substituir lazer por trabalho, expandindo a oferta de trabalho, a qual cresce em torno de $4 \%$ em relação ao equilíbrio de referência.

\footnotetext{
${ }^{8}$ No cálculo das alíquotas efetivas são consideradas as seguintes bases de incidência tributária expressas em percentual do PIB, obtidas a partir das contas nacionais: consumo das famílias $(61,6)$, excedente operacional bruto $(41,2)$, salários $(38,5)$, remuneração dos autônomos $(5,7)$, poupança $(18,1)$ e depreciação (3\% a.a.).

${ }^{9}$ Para isso utiliza-se o software SORITEC, o qual emprega o algoritmo de resolução Newton.
} 
Em relação aos inativos, mesmo inexistindo o efeito-substituição, verifica-se que o consumo também se expande. Neste caso, a magnitude do resultado também é influenciada pelo fato de se beneficiarem relativamente mais do que os ativos da redução do imposto sobre o consumo. No agregado, o consumo cresce em volume, sendo que o bem produzido para o mercado interno e o importado apresentam a mesma taxa de crescimento.

Em relação à produção, verifica-se que a expansão do consumo desloca o esforço produtivo para o atendimento do mercado interno em detrimento do externo. Dada a maior participação relativa do setor que produz para o mercado interno, a expansão da produção deste setor mais do que compensa a queda do setor exportador, fazendo com que o PIB cresça. Acompanhando o crescimento do PIB, o emprego também cresce.

A redução das exportações e o aumento das importações, gerados pela expansão do consumo, causam, por seu turno, a ampliação do déficit comercial e o aumento do endividamento externo. A expansão da poupança externa, por sua vez, possibilita financiar a expansão do investimento, mesmo com a diminuição da poupança nacional. A redução das receitas fiscais em 5\%, mantendo os gastos do governo, acaba provocando o aumento da relação dívida/PIB. Vê-se, portanto, que do ponto de vista fiscal, o efeito expansivo gerado pela redução do imposto não foi suficiente para compensar a queda na arrecadação tributária.

A redução das exportações e o aumento das importações, gerados pela expansão do consumo, causam, por seu turno, a ampliação do déficit comercial e o aumento do endividamento externo. A expansão da poupança externa, por sua vez, possibilita financiar a expansão do investimento, mesmo com a diminuição da poupança nacional. A redução das receitas fiscais em 5\%, mantendo os gastos do governo, acaba provocando o aumento da relação dívida/PIB. Vê-se, portanto, que do ponto de vista fiscal, o efeito expansivo gerado pela redução do imposto não foi suficiente para compensar a queda na arrecadação tributária.

\subsection{Simulação 2: Redução do imposto sobre a renda}

Diferentemente do ocorrido na situação anterior, neste caso não se verifica o efeito inicial sobre os preços. Entretanto, a redução da alíquota do imposto de renda acarreta uma maior expansão da oferta de trabalho do que no caso anterior. Como conseqüência, o consumo da população ativa se expande a uma taxa superior à verificada anteriormente. Deve-se considerar que, na primeira simulação, o efeitosubstituição gerado pela redução do imposto ocorre por meio da queda dos preços e da conseqüente elevação do salário real, sendo limitado, portanto, pela magnitude da propensão a consumir. No caso em consideração, a redução do imposto exerce um efeito direto sobre a renda, tornando mais evidente para as famílias a mudança no preço relativo do trabalho e do lazer.

No que se refere ao consumo, portanto, verifica-se, como na simulação anterior, que tanto o dos ativos quanto dos inativos se expande. Entretanto, conforme já mencionado, a expansão do consumo dos ativos é explicada pela ocorrência dos efeitos renda e substituição, enquanto que a dos inativos ocorre somente em função do segundo efeito.

No que concerne à produção, tendo em vista a maior expansão do consumo interno, observa-se um aprofundamento da transferência do esforço produtivo do setor exportador para o setor que produz para o mercado doméstico. Tal fato propicia um maior crescimento do PIB e do emprego do que no caso anterior. $O$ saldo da balança comercial e o endividamento externo também apresentam desempenhos relativamente piores.

\subsection{Simulação 3: Redução do imposto sobre o valor agregado compensada pela introdução de um imposto lump-sum}

Conforme já comentado, a redução do imposto sobre o valor agregado tem como efeito inicial a redução do preço do consumo interno, o que aumenta o poder de compra das famílias. Entretanto, 
Table 5: Resultados das simulações envolvendo alterações de política fiscal $\left({ }^{*}\right)$

\begin{tabular}{|c|c|c|c|c|c|}
\hline Variável & Sim-1 & Sim-2 & Sim-3 & Sim-4 & Sim-5 \\
\hline \multicolumn{6}{|c|}{ Famílias } \\
\hline Bem-estar & 2,62 & 3,67 & $-0,55$ & 0,76 & $-1,52$ \\
\hline Consumo do Bem1 & 0,46 & 0,68 & 0,02 & 0,24 & $-0,23$ \\
\hline Consumo do Bem2 & 0,46 & 0,68 & 0,02 & 0,24 & $-0,23$ \\
\hline Consumo dos ativos & 1,59 & 2,30 & 0,07 & 0,83 & $-0,83$ \\
\hline Consumo dos inativos & 0,62 & 0,90 & 0,001 & 0,30 & $-0,33$ \\
\hline Consumo agregado & 0,46 & 0,68 & 0,02 & 0,27 & $-0,23$ \\
\hline Lazer & $-1,46$ & 2,13 & $-1,54$ & $-2,19$ & 0,73 \\
\hline Poupança nacional & $-3,66$ & 3,46 & $-1,56$ & $-1,34$ & $-0,19$ \\
\hline \multicolumn{6}{|c|}{ Empresas } \\
\hline Produção do $B e m 1$ & 0,34 & 0,50 & 0,17 & 0,32 & $-0,17$ \\
\hline Produção do Bem3 & $-0,32$ & 0,47 & 6,21 & 5,94 & 0,11 \\
\hline Produção total & 0,28 & 0,41 & 0,72 & 0,84 & $-0,14$ \\
\hline Emprego & 0,25 & 0,37 & 0,69 & 0,80 & $-0,13$ \\
\hline Investimento & 0,28 & 0,41 & 0,72 & 0,84 & $-0,14$ \\
\hline Balança comercial ${ }^{(* *)}$ & $-0,07$ & $-0,11$ & 0,57 & 0,52 & 0,03 \\
\hline \multicolumn{6}{|c|}{ Preços } \\
\hline Preço do consumo & $-1,33$ & 0,00 & $-1,33$ & 0,00 & $-1,33$ \\
\hline Salário médio famílias & $-0,06$ & $-0,09$ & 0,01 & $-0,02$ & 0,03 \\
\hline Salário médio empresas & 0,05 & 0,07 & 0,05 & 0,07 & $-0,02$ \\
\hline Taxa de juros & 0,00 & 0,00 & 0,00 & 0,00 & 0,00 \\
\hline Taxa de juros das famílias & 0,00 & 0,00 & 0,00 & 0,00 & 0,00 \\
\hline \multicolumn{6}{|c|}{ Impostos } \\
\hline Valor agregado & 14,1382 & 15,6754 & 14,1382 & 15,6754 & 14,1382 \\
\hline Renda & 11,8161 & 10,0713 & 11,8161 & 10,0713 & 13,5631 \\
\hline Lump-sum & não & não & $\operatorname{sim}$ & $\operatorname{sim}$ & não \\
\hline Poupança & 13,2146 & 13,2146 & 13,2146 & 13,2146 & 13,2146 \\
\hline \multicolumn{6}{|c|}{ Equilíbrio do mercado de capitais ${ }^{(*)}$} \\
\hline$\frac{\triangle E M / n}{Y}$ & $-3,01$ & $-2,86$ & $-1,29$ & $-1,11$ & $-0,15$ \\
\hline$\frac{\Delta\left(K_{1}+K_{3}\right)}{Y}$ & 0,17 & 0,25 & 0,43 & 0,50 & $-0,09$ \\
\hline$\frac{\triangle D}{Y}$ & 3,34 & 3,34 & 0,00 & 0,00 & 0,00 \\
\hline$\frac{\triangle D X}{Y}$ & 0,22 & 0,32 & $-1,67$ & $-1,54$ & $-0,10$ \\
\hline
\end{tabular}

: Fonte: Cálculos dos autores. ${ }^{(*)}$ Os valores expressam a diferença percentual em relação ao equilíbrio de referência; ${ }^{(*)}$ em relação ao PIB. 
tem-se, agora, com a introdução do imposto lump-sum, a redução da renda familiar, o que acaba por limitar a expansão deste consumo. O resultado líquido é uma expansão do mesmo, embora a uma taxa inexpressiva. Verifica-se, ademais, que os inativos aumentam menos o consumo do que os ativos, o que se explica pelo fato de que a carga do imposto lump-sum é relativamente mais pesada para eles. A evolução do consumo de produtos nacionais e importados é similar, já que a taxa de câmbio não varia, não havendo, portanto, efeito substituição ocasionado pelos preços.

As empresas, por seu turno, são estimuladas a contratar e a investir mais com vistas à satisfação da demanda adicional. Todavia, diferentemente do verificado nas simulações precedentes, na situação em questão, o esforço produtivo se direciona principalmente para o setor produtor de bens exportáveis. Isto ocorre porque, enquanto as empresas do setor que produz para o mercado doméstico são restringidas pela demanda das famílias, as empresas do setor exportador podem aumentar a sua produção, já que sua demanda é perfeitamente elástica. Como resultado, o saldo comercial melhora e a dívida externa é reduzida.

Em se tratando da dívida interna, observa-se que ela permanece estável em virtude da hipótese adotada de manutenção da receita tributária estável. Este resultado, contudo, ocorre em função da hipótese de uma pequena economia aberta, na qual a taxa de juros doméstica é dada pelo mercado financeiro internacional.

\subsection{Simulação 4: Redução do imposto sobre a renda compensada pela introdução de um imposto lump-sum}

Da mesma forma que na Sim-2, neste caso não se constata o efeito inicial sobre os preços. Por outro lado, tanto a alteração do imposto de renda quanto à introdução de um imposto lump-sum, afetam a renda familiar. A redução do imposto sobre a renda acarreta a expansão da demanda de consumo das famílias, tanto dos ativos quanto dos inativos. No caso dos ativos, em virtude dos efeitos renda e substituição, e, no caso dos inativos, somente em função do segundo efeito. Em comparação com a Sim-3, esta política gera uma maior expansão da demanda de consumo das famílias. Tal fato decorre, pelos motivos já comentados, das magnitudes dos efeitos renda e substituição.

A produção global também se expande mais que no caso precedente. Isto porque, além de estimular o setor exportador, o maior aumento do consumo interno intensifica a produção doméstica. Como resultado, tem-se um maior crescimento do PIB e do emprego do que na simulação anterior.

Como reflexo do desempenho do setor exportador, verifica-se, à semelhança da simulação anterior, que tanto o déficit comercial quanto o estoque da dívida externa apresentam substancial redução. A dívida interna, por sua vez, permanece estável como conseqüência da restrição imposta à manutenção da receita fiscal estável.

\subsection{Simulação 5: Redução do imposto sobre o valor agregado compensada pelo aumento do imposto sobre a renda}

Esta simulação integra os efeitos das duas últimas simulações. Dado o tamanho relativo das bases de incidência tributária do consumo e da renda na economia brasileira, a magnitude de elevação da alíquota do imposto de renda, necessária para manter a receita tributária constante, é maior do que a sobre o consumo. Como conseqüência, tem-se que o efeito positivo sobre o consumo, provocado pela redução do imposto sobre o valor agregado, acaba por ser mais do que compensado pelo efeito negativo devido ao aumento do imposto sobre a renda. O efeito negativo sobre o consumo ocorre tanto na população ativa quanto na inativa.

Observa-se que o PIB, a produção, o emprego e o investimento diminuem em resposta à contração da demanda das famílias. Mas, se o nível de atividade das empresas que produzem para o mercado interno se contrai, o mesmo não acontece com aquelas que exportam, ocorrendo uma transferência de 
empregos para o setor exportador. A expansão das exportações, juntamente com a queda da demanda de importações, permite uma melhora da balança comercial e a redução da dívida externa.

$O$ efeito da política sobre o bem-estar apresenta-se como negativo, o que revela não parecer ser desejável a substituição de um imposto indireto sobre oconsumo por um imposto direto sobre a renda. Tal evidência confirma tanto os resultados apresentados por Schubert and Letournel (1991) quanto os apresentados por Auerbach and Kotlikoff (1987).

\section{COMENTÁRIOS FINAIS}

Utilizando-se de uma estrutura teórica de equilíbrio geral intertemporal, o modelo apresentado neste artigo permitiu uma análise dos efeitos de longo prazo sobre as variáveis econômicas oriundos de simulações envolvendo alterações na política tributária. Apesar de ser um modelo relativamente simples, ele evidenciou alguns aspectos importantes relacionados a este tipo de política. $\mathrm{O}$ mais relevante é o de que não é recomendável a substituição de um imposto indireto sobre o consumo por um imposto direto sobre a renda, mantendo o mesmo nível de receita pública. Tal evidência confirma os ensinamentos da teoria pertinente, mas vai contra os resultados obtidos em outros estudos, utilizando modelos estáticos. ${ }^{10}$

Nas alternativas tributárias que representam uma redução da carga tributária, Sim-1 e Sim-2, verificouse uma expansão do produto e do emprego. Em ambas, o consumo interno aumentou o que, devido ao pleno uso dos fatores produtivos, ocasionou um deslocamento de recursos para o setor produtor de bens destinados ao mercado doméstico. Como conseqüência, nos dois casos ocorreu um aumento do déficit comercial e do endividamento externo. O aumento da arrecadação com a expansão da atividade econômica não compensou a redução de receita com a redução dos impostos e, com isso, a dívida pública global aumentou.

A substituição de impostos diretos e indiretos por um imposto neutro ou lump-sum (Sim-3 e Sim-4) também mostraram resultados favoráveis sobre o produto e o emprego, embora, como era de se esperar, com impactos menos significativos que as políticas de redução de impostos. ${ }^{11}$ Nestes casos, a menor expansão do consumo fez com que o setor exportador apresentasse um desempenho relativamente melhor. Como resultado, o saldo comercial melhorou e a dívida externa diminuiu. A dívida interna, por seu lado, permaneceu estável pela constância da taxa de juros e da receita tributária.

Por fim, a redução do imposto sobre o valor agregado, compensada pelo aumento do imposto de renda (Sim-5), mostrou efeitos desfavoráveis sobre o produto e o emprego. O consumo doméstico se contrai, levando a uma realocação de recursos para o setor exportador. A expansão das exportações, juntamente com a queda da demanda de importação, permite uma melhora da balança comercial e a redução da dívida externa.

\section{BIBLIOGRAPHY}

Afonso, J. R., Araújo, E. A., Rezende, F., \& Varsano, R. (2000). A tributação brasileira e o novo ambiente econômico: A reforma tributária inevitável e urgente. Revista do BNDES, 7(13):137-170.

Ando, A. \& Modigliani, F. (1963). The "life cycle" hypothesis of saving: Aggregate implications and tests. American Economic Review, 53(1):55-84.

\footnotetext{
${ }^{10}$ É o caso, por exemplo, de Fochezatto (2003). Neste estudo, o autor trabalha com vários setores e grupos de famílias, capturando as interligações entre incidência tributária, os diferentes perfis de consumo e a estrutura produtiva setorial. Isto explica as diferenças de seus resultados com os obtidos neste trabalho.

${ }^{11}$ Isto, de certa forma, mostra que os atuais impostos, diretos e indiretos, são ineficientes. Ou seja, para uma mesma receita, seus custos econômicos são maiores que o imposto neutro.
} 
Auerbach, A. J. \& Kotlikoff, L. J. (1987). Dynamic Fiscal Policy. Cambridge University Press, Cambridge.

Ferreira, P. C. G. \& Araújo, C. H. V. (1999). Reforma tributária, efeitos alocativos e impactos de bem-estar. Revista Brasileira de Economia, 53(2):133-166.

Fochezatto, A. (2003). Reforma tributária, crescimento e distribuição de renda no Brasil: Lições de um modelo de equilíbrio geral computável. Revista de Economia Aplicada, 7(1):83-110.

Lledo, V. D. (2001). Tax reform under fiscal stress: A CGE analysis of the Brazilian tax reform. Disponível na internet: http://epge.fgv.br/portal/arquivo/1070.pdf.

Mercenier, J. \& Sampaio de Souza, M. C. (1994). Structural adjustment and growth in a highly indebted market economy: Brazil. In Mercenier, J. \& Srinivisan, T. N., editors, Applied General Equilibrium and Economic Development. University of Michigan Press, Ann Harbor.

Modigliani, F. \& Brumberg, R. (1954). Utility analysis and consumption function: An interpretation of cross-section data. In Kurithara, K., editor, Post-Keynesian Economics. Rutgers University Press, New Brunswick.

Oliveira, L. G. S. \& Lannes Jr, O. P. (2000). Reforma da Previdência Social com desequilíbrio orçamentário no regime de repartição: Uma análise de equilíbrio geral com restrições ao crédito. Brasília: Universidade de Brasília, Seminário 11/00.

Schubert, K. \& Letournel, P. (1991). Un modèle d'equilibre général appliqué à l'etude de la fiscalité française: Résultants de long terme. Economie et Prévision, 98:83-99.

Tourinho, O. A. F., Kume, H., \& Pedroso, A. C. S. (2002). Elasticidade de Armington para o Brasil. Texto para Discussão 901. Rio de Janeiro: BNDES. 